\title{
A ESTIGMATIZAÇÃO DO CRIMINOSO SOB A PERSPECTIVA DA CRIMINOLOGIA CRÍTICA: A SELETIVIDADE DO SISTEMA NA ABORDAGEM DO LABELLING APPROACH E A DA INIBIÇÃO REINTEGRADORA
}

\author{
Andressa Silveira Tanferri" \\ Gilberto Giacoia**
}

SUMÁRIO: Introdução; 2 A estigmatização do criminoso; 30 processo de criminalização de acordo com a teoria do Labelling Approach; 4 A teoria da inibição reintegradora; 50 papel da seletividade do controle social brasileiro na construção do estigma; 6 Considerações finais; Referências.

RESUMO: No direito penal sancionador é possível verificar um descompasso entre a sua interpretação e aplicação e os preceitos de justiça igualitária legalmente previstos, o que ocorre principalmente em razão da seletividade do sistema punitivo, influenciado por construções sociais quanto ao perfil do criminoso. O objetivo do presente trabalho é demonstrar como o processo de estigmatização é determinante para a seletividade na aplicação das normas penais, por intermédio da análise dos comportamentos desviantes e das abordagens criminológicas sobre a temática. $\mathrm{O}$ método utilizado é o dedutivo, com técnica de revisão bibliográfica e documental. Conclui-se, após a análise do estudo, que os fatores estigmatizantes estão enraizados na sociedade, nas normas e na atuação do Estado, assim, os efeitos da rotulação implicam diretamente na marginalização do sujeito e, consequentemente, refletem no perfil da população carcerária brasileira.

PALAVRAS-CHAVE: Estigmatização; Criminoso; Etiquetamento; Seletividade.

\section{THE STIGMATIZATION OF THE CRIMINAL FROM THE PERSPECTIVE OF CRITICAL CRIMINOLOGY: THE SYSTEM'S SELECTIVIT Y IN THE LABELING APPROACH AND REINTEGRATION INHIBITION}

ABSTRACT: Penal Law reveals a gap between interpretation and application and the precepts of legally foreseen equalitarian justice. This is mainly due to the selectivity

\footnotetext{
"Advogada, mestranda em Ciência Jurídica, pela Universidade Estadual do Norte do Paraná, UENP. Docente e coordenadora do Núcleo de Prática Jurídica da Unopar Londrina, Brasil. E-mail: andressatanferri@gmail.com ** Procurador de Justiça, professor na graduação e na pós-graduação da Universidade do Norte do Paraná (UENP), Pós-doutor pelas Universidades de Coimbra, UC, Portugal e Universidade de Barcelona, Espanha.
} 
of the punishment system affected by social constructs and the criminal's profile. Current paper demonstrates how the stigmatization process determines selectivity in the application of penal norms through the intermediation of deviate behavior and criminological approaches on the theme. The deductive method, coupled to a bibliographical and documentary review, reveals that stigmatizing factors are rooted in society, in norms and in the activities of the State. Labeling effects directly imply in the marginalization of the agent and, consequently, reflect the profile of the Brazilian prison inmates.

KEY WORDS: Stigmatization; Criminal; Labeling; Selectivity.

\section{LA ESTIGMATIZACIÓN DEL CRIMINAL BAJO LA PERSPECTIVA DE LA CRIMINOLOGÍA CRÍTICA: LA SELECTIVIDAD DEL SISTEMA EN EL ABORDAJE DEL LABELLING APPROACH Y LA DE LA INHIBICIÓN REINTEGRADORA}

RESUMEN: En el derecho penal sancionador es posible verificar un desajuste entre su interpretación y aplicación y los preceptos de justicia igualitaria legalmente previstos, lo que ocurre principalmente en razón de la selectividad del sistema punitivo, influenciado por construcciones sociales cuanto al perfil del criminal. El objetivo del presente estudio es demostrar cómo el proceso de estigmatización es determinante para la selectividad en la aplicación de las normas penales, por intermedio del análisis de los comportamientos desviantes y de los abordajes criminológicas sobre la temática. El método utilizado es el deductivo, con técnica de revisión bibliográfica y documental. Se concluye, tras el análisis del estudio, que los factores de estigmatización están enraizados en la sociedad, en las normas y en la actuación del Estado, así, los efectos de la rotulación implican directamente en la marginalización del sujeto y, consecuentemente, reflexionan en el perfil de la populación carcelaria brasileña.

PALABRAS CLAVE: Estigmatización; Criminal; Etiquetamiento; Selectividad.

\section{INTRODUÇÃO}

Há uma busca incessante da sociedade pela justiça, igualdade e democracia, fundada em preceitos constitucionalmente assegurados, porém, verifica-se na realidade jurídica brasileira, especialmente no que concerne ao direito penal, uma problemática em sua aplicação prática que acarreta na violação destes primados.

Ao invés de cumprir com as finalidades de prevenção e ressocialização almejadas, sustentando os seus fundamentos, o sistema punitivo acaba se mostrando 
condicionante e seletivo, notadamente no momento de interpretação e aplicação das normas, bem como na atuação das agências de criminalização secundária que efetuam o controle formal ostensivo.

Ao refletir sobre as contingências desse fenômeno social, dessume-se que a lógica da seletividade é marcada pela estigmatização, inicialmente realizada pela própria sociedade por intermédio de fatores culturais, econômicos, sociais e históricos que imprimem categorias de sujeitos sobre os quais recaem a maior parte do jus puniendi.

A reação social nos moldes atuais é uma verdadeira barreira à ressocialização, a teoria crítica do Labelling Approach, que será explorada no presente trabalho, aborda com enfoque criminológico a forma como a sociedade reage aos comportamentos humanos, definindo-os ou não como desviados. A partir da interação social, alguns indivíduos são etiquetados como delinquentes e passam a ser encarados como pessoas não confiáveis para viver de acordo com as regras do grupo.

Segundo a Teoria da Inibição Reintegradora, abordada no terceiro capítulo deste estudo, uma das vertentes modernas do Labelling Approach, a reação social é decisiva para que o indivíduo permaneça na carreira criminosa ou a abandone. Partindo desta premissa, observa-se a necessidade de uma mudança de paradigma social e cultural, uma vez que a resposta da comunidade tem funcionado apenas como fator inibitório e desintegrador do infrator.

Todavia, nota-se que a marginalização do criminoso não soluciona a desordem do sistema, sendo necessária a busca de alternativas para este desmesurado problema social. Desta feita, de acordo com a referida teoria, somente seria possível reverter a sistemática atual por meio da reintegração do sujeito à comunidade, com propostas concretas de política criminal que fortaleçam a consciência individual e que incutam nele uma vergonha capaz de causar uma mudança positiva em seu comportamento, rechaçando, pois, a ideia da estigmatização.

Por fim, conclui-se o estudo analisando o conceito de seletividade penal, buscando demonstrar que se trata de um mecanismo de controle social do direito penal fundamentado nas mazelas do estigma social. Nesse sentido, serão apontados os critérios de seleção utilizados pelo sistema penal, corroborados por uma breve análise de dados do sistema prisional brasileiro, a fim de demonstrar que determinadas estratificações sociais são comumente mais selecionadas do que outras.

O objetivo principal do presente estudo, consiste, pois, em fazer um para- 
lelo entre a seletividade do sistema punitivo nos moldes atuais e as teorias criminológicas apresentadas que tratam da rotulação do indivíduo e analisam a visão da sociedade frente ao criminoso, bem como estudam a dificuldade de desconstruir este paradigma social que o afasta da comunidade.

O método escolhido para desenvolver a pesquisa, de caráter eminentemente teórico, foi o dedutivo, com revisão bibliográfica e documental, partindo de premissas gerais e verdadeiras relacionadas à construção do estigma social do criminoso e objetivando chegar a uma conclusão específica a respeito da seletividade das instâncias de controle fundada nas teorias criminológicas, limitando-se à análise das teorias do Labelling Approch e da Inibição Reintegradora.

\section{A ESTIGMATIZAÇÃO DO CRIMINOSO}

O estigma, que no latim significa tatuagem, pode ser definido como uma marca, uma característica que diferencia o sujeito que a porta dos demais. O termo foi criado na Grécia antiga e dizia respeito às evidências corporais que destacavam o indivíduo, em regra negativamente, demonstrando o seu status moral perante à sociedade.

Utilizado posteriormente pela sociologia, a expressão passou a se referir a uma característica objetiva, não necessariamente ligada ao corpo, que recebe valoração social negativa e depreciativa e que define a identidade do indivíduo no meio social. De acordo com o conceito trazido por Lemert ${ }^{03}$,

A estigmatização descreve um processo que vincula sinais visíveis de inferioridade moral a pessoas, tais como rótulos, marcas e informações divulgadas publicamente. No entanto, define mais do que a ação formal de uma comunidade em relação a um membro com comportamento inadequado ou fisicamente diferente. Rituais de degradação, como surrar o covarde do regimento, administrar o juramento do mendigo, diagnosticar a doença contagiosa e considerar o acusado cul-

\footnotetext{
${ }^{03}$ LEMERT, Edwin M. Human deviance, social problems, and social control. Londres: Prentice-Hall International, 1967, p. 42. No original: "Stigmatization describes a process attaching visible signs of moral inferiority to persons, such as individious labels, marks, brands, or publicly dissaminated information. However, it defines more than the formal action of a community toward a inisbehaving or physically different member. Degradation rituals, such as drumming the coward out of the regiment, administering the pauper's oath, diagnosing the contagious illness, and finding the accused guilty as charged may dramatize the facts os devianc, but their "success" is gauged less by their manner of enactment than by their prevailing consequences".
} 
pado podem dramatizar os fatos do desvio, mas seu "sucesso" é medido menos pela sua maneira de promulgar do que pelas suas consequências (tradução livre).

A sociedade institui os meios de categorizar as pessoas e os atributos considerados comuns e naturais para os membros de cada uma dessas categorias ${ }^{04}$. Assim, a primeira atitude que se toma frente ao estranho e desconhecido é catalogá-lo em uma das categorias que se conhece, de acordo com a sua "identidade" ou "status social", ainda que de forma inconsciente. Para Goffman" "o estigma é, portanto, um tipo especial de relação entre atributo e estereótipo".

Nesse cariz, parte-se do pressuposto de que os desvios de conduta não são mais simples qualidades, atos ou características individuais que estão presentes em alguns sujeitos. Para ser considerado um desviante ou outsider, de acordo com a terminologia introduzida por Howard Becker, não é preciso muito, basta ser diferente do "comum" ou fora da média que certa sociedade entende por "natural", ou seja, "quando uma regra é imposta, a pessoa que presumivelmente a infringiu pode ser vista como um tipo especial, alguém de quem não se espera viver de acordo com as regras estipuladas pelo grupo. Essa pessoa é encarada como um outsider" ${ }^{06}$.

Subsumindo este conceito aos preceitos do direito penal sancionador, aquele que não age de acordo com as normas previstas no ordenamento jurídico é considerado diferente pela sociedade, sendo assim, independentemente do desvio praticado, mas desde que contrário à norma penal, será a partir daí classificado como criminoso.

A construção do estigma na seara punitiva pode ser ocasionada por uma soma de fatores. Em uma análise detalhada é possível, portanto, identificar, do descobrimento do fato desviante até o cumprimento integral de sua punição/consequência, momentos distintos em que se marca o sujeito como criminoso.

Primeiramente, o processo de estigmatização é praticado pelos próprios agentes de controle social ostensivo, quando se seleciona o suspeito de acordo com as suas características pessoais. Em regra, a seleção é discriminatória e ocorre com base no perfil de criminoso culturalmente construído, sendo em sua maioria pobre,

${ }^{04}$ GOFFMAN, Erving. Estigma: Notas Sobre a Manipulação da Identidade Deteriorada. Rio de Janeiro: LTC, 1988, p. 5.

${ }^{05}$ Ibid., p. 7.

${ }^{06}$ BECKER, Howard Saul. Outsiders: Estudos de sociologia do desvio. Zahar: Rio de Janeiro, 2008. Título original: Outsiders: studies in the sociology of deviance, p. 15. 
negro e morador da periferia. Nesse sentido, cabe a reflexão de Baratta acerca da seletividade do sistema.

Se partirmos de um ponto de vista mais geral, e observarmos a seleção da população criminosa dentro da perspectiva macrossociológica da interação e das relações de poder entre os grupos sociais, reencontramos, por detrás do fenômeno, os mesmos mecanismos de interação, de antagonismo e de poder que dão conta, em uma dada estrutura social, da desigual distribuição de bens e de oportunidades entre os indivíduos. Só partindo deste ponto de vista pode-se reconhecer o verdadeiro significado do fato de que a população carcerária, nos países da área do capitalismo avançado, em sua enorme maioria, seja recrutada entre a classe operária e as classes economicamente mais débeis ${ }^{07}$.

Assim, após ser acusado como suspeito da prática do fato, ainda que em sede investigativa, o sujeito selecionado será automaticamente classificado como criminoso por aqueles que o circundam, muitas vezes pela mídia e, consequentemente, pela sociedade como um todo.

Posteriormente, no curso do processo, após denunciado, passa a confirmar a sua identidade social como criminoso, que é corroborada com a condenação, enterrando qualquer possibilidade de se desfazer o estereótipo adquirido.

A partir daí, surge um caminho sem volta, pois o sujeito será inserido no sistema prisional para cumprir a pena e, mesmo após a quitação total de sua dívida social, adjetivos como "criminoso", "marginal", "prisioneiro", "egresso", jamais o abandonarão.

Enquanto especialistas como juristas e cientistas sociais analisarão a questão da culpa à sua moda, uma terceira perspectiva integra os pensamentos da maioria das pessoas - incluindo muitos profissionais da justiça criminal. Trata-se de um conceito mais moralista ou "imputativo". Na visão popular, a culpa não é meramente uma descrição de comportamento, mas uma afirmação de qualidade moral. A culpa diz algo sobre a qualidade da pessoa que praticou o ato e tem uma caracte-

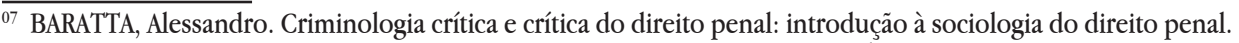
Tradução Juarez Cirino dos Santos. 3.ed. Rio de Janeiro: Revan, 2002, p. 106. 
rística indelével e bastante "adesiva". A culpa adere à pessoa de modo mais ou menos permanente, e há poucos solventes conhecidos. Em geral ela se torna uma característica primária que define a pessoa. A pessoa culpada de um roubo se torna um ladrão, um criminoso. Uma pessoa que foi aprisionada se torna um ex-presidiário, um ex-criminoso, e isso passa a fazer parte de sua identidade, sendo difícil de eliminar ${ }^{08}$.

É possível identificar que uma das grandes problematizações da reincidência se dá por meio dos estigmas. O sujeito sofre uma carga valorativa tão forte em sua vida no cárcere que, ao retornar ao convívio social, não consegue transcender tal perspectiva e tende a voltar para o local de onde saiu, qual seja, a penitenciária.

Com a estigmatização, o sujeito tem sua identidade social anterior substituída pela construção social e valorativa a respeito do seu passado, muitas vezes pelo que é e não pelo que efetivamente fez, o que o exclui do "círculo da normalidade", inclusive como se não fosse completamente humano, como bem explica Goffman.

Por definição, é claro, acreditamos que alguém com um estigma não seja completamente humano. Com base nisso, fazemos vários tipos de discriminações através das quais efetivamente, e muitas vezes sem pensar, reduzimos suas chances de vida: construímos uma teoria do estigma; uma ideologia para explicar a sua inferioridade e dar conta do perigo que ela representa, racionalizando algumas vezes uma animosidade baseada em outras diferenças, tais como as de classe social ${ }^{09}$.

A segregação, o preconceito e a discriminação dos marcados pelos sinais da pena, ou mesmo do processo penal, dificulta e por vezes impede qualquer espécie de aceitação e reinserção desses indivíduos no meio social, o que, por conseguinte, faz com que eles reduzam o seu nível de identidade real e incorporem de forma definitiva a identidade negativa socialmente atribuída. Goffman bem descreve essa barreira da sociedade em aceitar o estigmatizado.

\footnotetext{
${ }^{08}$ ZEHR, Howard. Changing Lenses: A New Focus for Crime and Justice (Trocando as Lentes: Um Novo Foco sobre Crime e a Justiça) - Scottsdale, PA: Herald Press, p. 66.

${ }^{09}$ GOFFMAN, Erving. Estigma - Notas Sobre a Manipulação da Identidade Deteriorada. Rio de Janeiro: Editora LTC, 1988, p. 8.
} 
Aqueles que têm relações com ele não conseguem lhe dar o respeito e a consideração que os aspectos não contaminados de sua identidade social os haviam levado a prever e que ele havia previsto receber; ele faz eco a essa negativa descobrindo que alguns de seus atributos a garantem ${ }^{10}$.

Em outra perspectiva, para Bacila, ${ }^{11}$ os estigmas funcionam como metarregras, pois, condicionam na prática o comportamento humano, assim como direcionam a atividade do sistema penal e, com base na crença em valores equivocados, atuam como verdadeiras regras e princípios paralelos a serem aplicados e obedecidos pelo corpo social, como será melhor detalhado no tópico relativo à seletividade.

Por tudo quanto analisado neste capítulo, é possível deduzir que o estigma é um fator que não se coaduna com a ideia de direito e igualdade. A partir do estudo do processo de estigmatização proveniente de comportamentos desviantes e supostamente contrários às normas penais, surgiram teorias criminológicas que buscam analisá-lo de forma crítica, em especial destaca-se a teoria do Labelling Approach, que analisa a criminalidade na perspectiva da reação social e suas consequências negativas na rotulação do indivíduo.

\section{O PROCESSO DE CRIMINALIZAÇÃO DE ACORDO COM A TEORIA DO LA- BELLING APPROACH}

A criminologia, ao contrário do direito penal, que traduz o crime como um fato típico, ilícito e, portanto, culpável, o encara como um problema social e busca identificar os fatores criminógenos que levaram o ser humano a praticar o fato desviante das normas sociais.

Após décadas de estudos que transitam de explicações biológicas e patológicas para justificarem o crime e suas causas sociais, chega-se modernamente ao surgimento de uma criminologia mais radical - em comparação às teorias consensuais da criminologia tradicional -, que critica o direito penal e o sistema punitivo como forma de controle social e analisa o processo de criminalização a partir da reação social, fundada em ideologias e interesses de determinada sociedade.

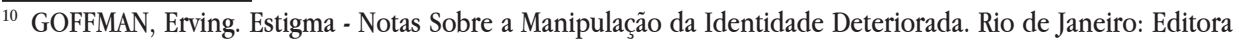
LTC, 1988, p. 11.

${ }^{11}$ BACILA, Carlos Roberto. Criminologia e estigmas: um estudo sobre os preconceitos. 4. ed. São Paulo: Atlas, 2015, p. 132. 
A teoria do Etiquetamento, também denominada de Labelling Approach, Interacionista ou da Rotulação Social, surgiu na década de 60 nos Estados Unidos da América e marcou a passagem da criminologia liberal para a criminologia crítica, pois contribuiu para a superação do paradigma etiológico em benefício do estudo das reações oriundas da sociedade sobre as instâncias de controle social, vistas sob 0 viés constitutivo diante da criminalidade ${ }^{12}$.

Segundo esse entendimento, a criminalidade não é uma propriedade inerente a um sujeito, mas uma "etiqueta" atribuída a certos indivíduos que a sociedade entende como delinquentes. Em outras palavras, o comportamento desviante é aquele rotulado como tal.

[...] o Labelling parte dos conceitos de 'conduta desviada' e 'reação social' como termos reciprocamente independentes, para formular sua tese central: a de que o desvio - e a criminalidade - não é uma qualidade intrínseca da conduta ou uma entidade ontológica pré-constituída à reação social (ou controle social), mas uma qualidade (etiqueta) atribuída a determinados sujeitos através de complexos processos de interação social, isto é, de processos formais e informais de definição e seleção $0^{13}$.

Com o surgimento desta teoria, surgem novos questionamentos, pois não se indaga mais o porquê do criminoso cometer crimes, mas por que algumas pessoas são tratadas como criminosos, quais as consequências desse tratamento e qual a fonte de sua legitimidade ${ }^{14}$.

Assim, surgem questões sobre o desvio, o poder da reação social, a delinquência, as formas de criminalização, os agentes de controle, os processos e os meios que a sociedade usa para definir as pessoas, quais as condutas sociais tidas como desviantes, ou seja, ocorre uma mudança na roupagem do estudo das questões de cunho criminal.

Para compreender melhor a teoria, impende-se explicitar o que seria um desvio nessa perspectiva. $\mathrm{O}$ ato desviante pode ser, pois, classificado como uma soma de dois fatores, de um lado deve-se verificar a sua natureza, se ele viola alguma regra, e de outro é preciso analisar como as pessoas reagem frente a ele, ou seja,

\footnotetext{
${ }^{12}$ BARATTA, Alessandro. Criminologia crítica e crítica do direito penal: introdução à sociologia do direito penal. Tradução Juarez Cirino dos Santos. 3.ed. Rio de Janeiro: Revan, 2002, p. 142.

${ }^{13}$ ANDRADE, Vera Regina Pereira de Andrade. A ilusão da segurança jurídica: do controle da violência à violência do controle penal. Porto Alegre: Livraria do Advogado, 1997, p. 205.

${ }^{14}$ SHECAIRA, Sérgio Salomão. Criminologia. 5 ed. rev. São Paulo: Editora Revista dos Tribunais, 2013, p.254.
} 
se a reação social é negativa. Becker resume objetivamente o desvio no seguinte ensinamento:

Se um ato é ou não desviante depende de como as pessoas reagem a ele. [...] O simples fato de uma pessoa ter cometido uma infração a uma regra não significa que outros reagirão como se isso tivesse acontecido. (Inversamente, o simples fato de ela não ter violado uma regra não significa que não possa ser tratada, em algumas circunstâncias, como se o tivesse feito ${ }^{15}$.

Complementando, o referido autor aduz que o grau em que um ato será tratado como desviante depende também de quem o comete e de quem se sente prejudicado por ele, pois regras tendem a ser aplicadas mais a algumas pessoas que a outras ${ }^{16}$.

À luz desse panorama, dessume-se que o mesmo comportamento que autoriza mandar alguém à prisão, também autoriza a qualificar outro como honesto, já que a imputação valorativa do ato está sujeita às circunstâncias em que ele se realiza e ao temperamento e apreciação da audiência que o testemunhou. ${ }^{17}$

Por esta razão, a teoria do Etiquetamento foca a sua pesquisa na reação social, ou seja, na interação entre o ato praticado e a sociedade, pois ela será determinante para a criminalização da conduta.

Para os autores do Labelling Approach a conduta desviante é o resultado de uma reação social e o delinquente se distingue do homem comum devido à estigmatização que sofre. Daí o tema central desta teoria ser precisamente o estudo do processo de interação, o qual o indivíduo é chamado de delinquente ${ }^{18}$.

O comportamento desviante relacionado à criminalidade é classificado pela presente teoria como primário ou secundário. Para Lemert ${ }^{19}$, a noção de desvio primário é associada a defeitos físicos, transtornos mentais, incapacidades pessoais, alcoolismo, prostituição, uso de drogas, enfim, ele ocorre em decorrência de fatores sociais, culturais, psicológicos ou fisiológicos. Embora seja reconhecido e considera-

\footnotetext{
${ }^{15}$ BECKER, Howard Saul. Outsiders: Estudos de sociologia do desvio. Rio de Janeiro: Zahar, 2008. Título original: Outsiders: studies in the sociology of deviance, p. 24.

${ }^{16}$ Ibid., p. 25.

${ }^{17}$ SHECAIRA, Sérgio Salomão. Criminologia. 5 ed. rev. São Paulo: Revista dos Tribunais, 2013, p.258.

${ }^{18}$ Ibid., p. 253.

${ }^{19}$ LEMERT, Edwin M. Human deviance, social problems, and social control. Londres: Prentice-Hall International, 1967, p 40.
} 
do indesejado pela sociedade, o desvio primário tem implicações na marginalização ligada ao psíquico e status do indivíduo.

Sendo assim, pode-se compreender o desvio primário como a primeira violação à norma ou ação delitiva do sujeito, cuja causa em regra envolve alguma finalidade ou necessidade pessoal, determinada por algum dos fatores anteriormente mencionados.

Já o desvio secundário refere-se a uma classe especial de atitudes tomadas pelas pessoas em resposta aos problemas criados pela reação da sociedade ao seu desvio. Estes problemas são essencialmente morais e giram em torno da estigmatização, punição, segregação e controle social, se tornando fatos centrais da existência para aqueles que o experimentam, alterando a estrutura psíquica, seu papel social, atitudes e autoestima. Quando são abarcadas pelo desvio secundário, a vida e a identidade da pessoa passam a ser organizadas em torno dos fatos do desvio. ${ }^{20}$

A própria punição aplicada ao desvio primário possui efeito criminógeno potencializador, que consolida o status de delinquente, gerando estereótipos e etiologias que o sistema teoricamente deveria evitar. Destarte, as consequências da reação social negativa, da incriminação, da rotulação e da estigmatização traduzem o desvio secundário, cujos efeitos são deveras danosos e modificam a própria identidade social do indivíduo e a maneira como ele se coloca - ou se exclui - na sociedade, assumindo o papel que lhe foi imposto, culminando por aumentar o índice de reincidência criminal.

De maneira bastante cruel, pode ser dito que, à medida que o mergulho no papel desviado cresce, há uma tendência para que o autor do delito defina-se como os outros o definem. [...] Surgirá uma espécie de subcultura delinquente facilitadora da imersão do agente em um processo em espiral que traga o desviante cada vez mais para a reincidência. ${ }^{21}$

Independente de todas as ações anteriores praticadas pelo sujeito, mesmo que predominantemente 'positivas', basta, pois, um único desvio à norma criminal, ainda que de menor relevância ou ofensividade, para a sociedade julgar o seu caráter

${ }^{20}$ LEMERT, Edwin M. Human deviance, social problems, and social control. Londres: Prentice-Hall International, 1967 , p. 40-41.

${ }^{21}$ SHECAIRA, Sérgio Salomão. Criminologia. 5. ed. rev. São Paulo: Revista dos Tribunais, 2013, p.256. 
e inseri-lo em uma categoria irreversível.

A concepção de crime como produto de normas (criação do crime) e de poder (aplicação de normas) define a lei e o processo de criminalização como "causas" do crime, rompendo o esquema teórico do positivismo e dirigindo o foco para a relação entre estigmatizarão criminal e formação de carreiras criminosas: a criminalização inicial produz estigmatização que, por sua vez, produz criminalizações posteriores (reincidên(ias) $)^{22}$.

A crítica principal da teoria gira, portanto, em torno do sistema punitivo nos moldes sancionador e segregador. A sede de punir da sociedade, reafirmada pelo conjunto de normas penais e efetivada pelo controle social ostensivo do Estado, tem uma função proliferadora da criminalidade e geradora de desigualdades.

Em termos gerais, é possível definir como lição precípua da teoria a afirmação de que o sujeito se torna aquilo que os outros enxergam dele e, de acordo com este mecanismo, a sistemática processual e a pena cumprem uma função reprodutora: a pessoa rotulada como delinquente assume, finalmente, o papel que lhe é consignado, comportando-se de acordo com ele. Todo o aparato do sistema penal está voltado para essa rotulação e para o reforço desses papéis. ${ }^{23}$

Como alternativa à crescente rotulação, a par das críticas realizadas, a teoria refuta o princípio da intervenção ou do fim penal, força motriz do perverso processo de etiquetamento, bem como a ideologia da ressocialização, sugerindo como menos prejudicial a denominada "prudente não-intervenção", calcada no objetivo de repensar o ordenamento penal em face de uma sociedade aberta, democrática e pluralista, expandindo os limites da tolerância para a superação dos conflitos e tensões sociais.

\section{A TEORIA DA INIBIÇÃO REINTEGRADORA}

A Teoria da Inibição Reintegradora, por sua vez, é uma vertente moderna da teoria do Etiquetamento, que toma como ponto de partida de forma parcialmente semelhante o estudo da criminalidade com base na reação social frente ao ato

22 SANTOS, Juarez Cirino dos. A criminologia radical. 3 ed. Curitiba: ICPC: Lumen Juris, 2008, p. 20.

${ }^{23}$ ZAFFARONI, Eugenio Raúl. Em busca das penas perdidas. 5. ed. Rio de Janeiro: Revan, 2001, p. 60. 
desviante praticado. Com vistas a dar um novo viés àquela teoria, propõe-se uma abordagem interacionista, uma vez que a reposta da comunidade tem funcionado apenas como fator inibitório e desintegrador do infrator.

Ao criar a teoria da Inibição Reintegradora (Reintegrative Shaming), Braithwaite aduz que a reação social é a chave tanto para a prevenção delitiva, se positiva, quanto para a marginalização definitiva do indivíduo que praticou algum tipo de infração, ou seja, quando a reação social diante de um fato delitivo desperta em seu autor uma vergonha que o faz reconciliar-se com a sociedade - ao invés de estigmatizá-lo -, aquele tenderá a não voltar a delinquir ${ }^{24}$.

Em oposição à estigmatização apontada pelo Labelling Approach, a qual se identifica com uma espécie de "vergonha desintegrativa", que tende a isolar o indivíduo da comunidade e induzi-lo ao crime, Braithwaite propõe uma "vergonha reintegrativa", na qual a manifestação de reprovação social é seguida de atos de reaceitação, que interrompem a assimilação do papel social de criminoso e, por via de consequência, impedem a reincidência ${ }^{25}$.

Com um grande número de pessoas estigmatizadas, ocorre o surgimento de grupos subculturais que fornecem ambientes de aprendizagem para o crime e oportunidades ilegítimas, sendo que os indivíduos estigmatizados possuem fortes tendências a participar de tais grupo porque são excluídos da sociedade convencional. Além disso, o processo de estigmatização tem um efeito de feedback que corrói o comunitarismo, tendo como resultado final uma sociedade com alta taxa de criminalidade ${ }^{26}$.

De acordo com o proposto pela teoria, a sociedade deveria incutir a vergonha àquele que praticou o ato criminoso, pois a vergonha gerada pelo fato praticado seria mais eficaz do que os métodos tradicionais retributivos de aplicação da pena no processo de ressocialização.

A tese central da teoria é que o crime é maior quando a vergonha é estigmatizante e menor quando é reintegrativa. Esta tese explica por que algumas sociedades têm índices mais altos de criminalidade do que outras e por que algumas pessoas são mais propensas a ofender outras (tradução livre) ${ }^{27}$.

\footnotetext{
${ }_{24}$ BRAITHWAITE, John. Crime, Shame, and Reintegration. New York: Cambridge University, 1999, p. 12-13.

${ }^{25}$ BENEDETTI, Juliana Cardoso. A justiça restaurativa de john braithwaite: Vergonha reintegrativa e regulação responsiva. Revista Direito GV, São Paulo, v. 1, n. 2, p.209-216, jun. 2005. Disponível em: http://bibliotecadigital.fgv.br/ojs/index.php/revdireitogv/article/view/35237/34037. Acesso em: 16 abr. 2018, p. 210.

${ }^{26}$ BRAITHWAITE, op. cit., p. 286.

${ }^{27}$ Ibid., p. 286. No original: "Braithwaites central thesis is that crime is higher when shaming is stigmatizing and lower when shaming is reintegrative. This thesis explains both why some societies have higher rates of crime than others and why some individuals are more likely to offend that others".
} 
Partindo da análise crítica à teoria do Etiquetamento, o autor assinala como uma grave falha do Labelling Approach o fato de essa perspectiva ter se ocupado somente do aspecto negativo da vergonha presente no processo de etiquetamento. De acordo com o teórico, a vergonha, praticada em regra por meio de cerimônias públicas de perdão e arrependimento, é um fator necessário para o controle social, desde que o foco seja voltado ao fato criminoso e não a pessoa que o praticou. Sendo a questão chave aquilo que segue a vergonha: reintegração ou estigmatização. A reintegração é essencial, pois os indivíduos envergonhados estão em um ponto de virada em suas vidas - uma época em que podem se reconectar à sociedade convencional ou aprofundar seu compromisso com o crime ${ }^{28}$.

Ademais, ao contrário dos teóricos da rotulagem, Braithwaite acredita que a intervenção do Estado também é necessária e critica aquela teoria por não haver vislumbrado outra solução que não a simplista não intervenção. Assim, o autor não nega a aplicação formal da punição pelo Estado, mas entende imprescindível a participação da comunidade no processo de desaprovação do crime e consequente provocação da vergonha na esfera individual do desviado, pois quando existem relações sociais de qualidade, elas fornecem os meios essenciais para que os infratores recebam o perdão e apoio necessários para se tornarem membros da comunidade.

Assim, o primeiro passo para a teorização produtiva sobre o crime é pensar na alegação de que rotular os infratores piora as coisas, uma vez que "a chave para o crime é o compromisso cultural de envergonhar de maneiras que são reintegradoras" (tradução livre) ${ }^{29}$.

É salutar mencionar, para a melhor compreensão da teoria, que quanto maior a relação de interdependência entre os indivíduos de determinada sociedade, mais eles terão a perder com a prática delitiva, como emprego, família, amigos, status e, portanto, serão mais suscetíveis à vergonha reintegradora, em uma relação diretamente proporcional. Nada tem maior força simbólica na construção de consciência em toda a comunidade do que o arrependimento.

De acordo com a teoria, o elemento preponderante para a compreensão do

${ }^{29}$ Ibid., p . 287. No original: "The theory in this book suggests that the key to crime control is cultural commitments to shaming in ways that I call reintegrative". 
crime não é a tipificação atribuída pelas instâncias de controle a um determinado comportamento, mas o consenso impregnado na sociedade quanto à criminalização de certas condutas. Pois, para Braithwaite, existe um consenso do qual também partilha o ofensor em torno da reprovação de determinados comportamentos, independentemente da definição a eles alocada pelo Estado $^{30}$.

Desta forma, a "vergonha reintegrativa" apenas será de fato exercida pela comunidade caso esteja claramente sedimentada entre os seus membros a reprovabilidade social da conduta praticada, o que só ocorre, justamente, no que toca aos "crimes predatórios" ${ }^{1}$. Os denominados "crimes predatórios" de acordo com a expressão utilizada pelo autor, seriam aqueles onde há um consenso na sociedade a respeito de sua contrariedade à norma e gravidade, pois chocam a sociedade $\mathrm{e}$ são facilmente perceptíveis, como os crimes contra a pessoa, contra o patrimônio, contra a dignidade sexual.

Ocorre que, por vezes, a conexão entre o fato praticado e a consequência social do crime não é claramente percebida pela comunidade, notadamente nos crimes contra o patrimônio público praticados por aqueles que detém um status social elevado (crimes do colarinho branco). Na maioria destes casos, que são tão graves quanto os predatórios e com consequências ainda mais nefastas, a sociedade não consegue realizar uma ligação direta entre a conduta e o resultado, como, por exemplo, não imputa a morte de milhares de pessoas decorrentes da deficiência na prestação de serviços de saúde ou de segurança pública ao sujeito que praticou crimes de corrupção e lavagem de dinheiro.

Nestes casos, nem sempre há consenso quanto à reprovabilidade das condutas, não raro isto ocorre pela própria ignorância da comunidade, então será preciso solidificar a reação social a respeito destas condutas delitivas, pois só a partir do consenso será possível funcionar de forma regular a aplicação da teoria proposta.

Verifica-se, pois, que a teoria estudada se trata de um prelúdio à justiça restaurativa, que posteriormente foi explorada pelo mesmo autor. Sendo assim, para que se alcance o controle e prevenção da criminalidade é mister que a sociedade prefira a inibição reintegradora à estigmatização, que opte pela reparação e reconciliação ao invés de simplesmente privar o agressor de liberdade ${ }^{32}$.

\footnotetext{
${ }^{30}$ BENEDETTI, Juliana Cardoso. A justiça restaurativa de john braithwaite: Vergonha reintegrativa e regulação responsiva. Revista Direito GV, São Paulo, v. 1, n. 2, p.209-216, jun. 2005. Disponível em: http://bibliotecadigital.fgv.br/ojs/index.php/revdireitogv/article/view/35237/34037. Acesso em: 16 abr. 2018, p. 211.

${ }^{31}$ BRAITHWAITE, John. Crime, Shame, and Reintegration. New York: Cambridge University, 1999, p. 13-14.

${ }^{32}$ BRAITHWAITE, John. Crime, Shame, and Reintegration. New York: Cambridge University, 1999, p. 287.
} 


\section{O PAPEL DA SELETIVIDADE DO CONTROLE SOCIAL BRASILEIRO NA CONS- TRUÇÃO DO ESTIGMA}

De acordo com o preceito constitucional previsto no art. $5^{\circ} \mathrm{da}$ Constituição Federal, é garantido a todos o tratamento isonômico perante a lei, independentemente de qualquer particularidade do indivíduo que o diferencie materialmente dos demais ou o inclua em algum tipo de minoria social.

Em que pese tal assertiva seja um direito fundamental de primeira geração, considerado cláusula pétrea e inviolável frente ao sistema jurídico, denota-se que o direito penal brasileiro, que abarca o sistema punitivo adotado, por meio dos seus agentes de controle formal, acaba por selecionar aqueles aos quais a lei deve ser de fato aplicada.

Não se trata aqui de discutir a criminalização primária e a forma, por vezes injusta, de elaboração das leis ou os seus fundamentos calcados em políticas criminais duvidosas e de caráter simbólico. Mas de se analisar de forma crítica o porquê destas regras pré-existentes não serem aplicadas equanimemente a todos aqueles que aderem, mesmo implicitamente, às normativas da sociedade onde vivem e, ainda, de que forma é feita a tendenciosa seleção dos sujeitos aos quais ela será aplicada.

Por mais que se busque normas jurídicas de caráter geral, abstrato e não discriminatório, é certo que sua aplicação não será livre de conceitos ou preconceitos, intuições, preferências, hábitos ou experiências, pois dependem da ação e interpretação de seres humanos, sujeitos a todas estas influências subjetivas. Ao atuar em nome do Estado, único detentor do jus puniendi, o sujeito deve se obrigar a agir com imparcialidade, mas, partindo-se de uma análise moral, sabe-se que a total isenção é um ideal impossível de ser atingido.

Para Bacila ${ }^{33}$, estes fatores subjetivos que acabam por influenciar as ações e decisões dos representantes do Estado constituem-se em regras, que vão além das regras jurídicas e seriam denominadas de metarregras, que também são estipuladas pela sociedade, por vezes de forma inconsciente. Trazendo o conceito de Baratta, "metarregras são mecanismos constituídos de regras, princípios e atitudes subjetivas

33 BACILA, Carlos Roberto. Criminologia e estigmas: um estudo sobre os preconceitos. 4. ed. São Paulo: Atlas, 2015, p. 17. 
que influenciam o operador do direito no momento de aplicação da regra jurídica ${ }^{34}$ ".

O estigma, portanto, também é uma metarregra de forte influência na seleção do sistema punitivo. Os estigmas culturalmente construídos, especialmente aqueles relacionados à posição social e etnia do indivíduo, são fatores inerentes à atuação seletiva do controle social. "É como se a metarregra fosse: o estigmatizado é o alvo a ser atingido" 35 .

Com base na construção do estigma justificada pelas teorias anteriormente apresentadas, é inegável que a sistemática do processo penal e o consequente encarceramento possuem efeitos estigmatizantes irreversíveis na identidade do sujeito, tanto individualmente como perante à sociedade. Porém, esses efeitos da aplicação efetiva da lei penal, na maioria dos casos, apenas incidem em face da estigmatização cultural que esse sujeito já sofria e que o levou a ser selecionado pelos agentes de controle formal como merecedor da sanção.

Enquanto os estudos empíricos demonstram o caráter majoritário e ubíquo do comportamento criminal, a etiqueta do criminoso, não obstante, manifesta-se como um fator negativo que os mecanismos do controle social repartem com o mesmo critério de distribuição dos bens positivos (fama, riqueza, poder etc.): o status e o papel das pessoas. De modo que as chances e riscos de ser etiquetado como delinquente não dependem tanto da conduta executada (delito) como da posição do indivíduo na pirâmide social (status) ${ }^{36}$.

Ainda nesta linha de intelecção, Baratta ${ }^{37}$, critica a função desenvolvida pelo sistema penal na conservação e reprodução da realidade social, que por si só já é desigual, atribuindo a culpa inicialmente à seletividade na aplicação das sanções penais estigmatizantes, especialmente o cárcere, que além de incidir negativamente no status social dos indivíduos, ainda impedem a sua ascensão social, contribuindo para a manutenção da escala vertical da sociedade; e em segundo lugar à função simbólica da pena, que ao coibir certos comportamentos ilegais serve para encobrir um número mais amplo de comportamentos delitivos de classes mais abastadas -

\footnotetext{
${ }^{34}$ BARATTA, Alessandro. Criminologia crítica e crítica do direito penal: introdução à sociologia do direito penal. Tradução Juarez Cirino dos Santos. 3. ed. Rio de Janeiro: Revan, 2002, p. 105.

35 BACILA, Carlos Roberto. Criminologia e estigmas: um estudo sobre os preconceitos. 4. ed. São Paulo: Atlas, 2015, p. 135.

${ }^{36}$ MOLINA, Antonio García-Pablos de. O que é criminologia? São Paulo: Revista dos Tribunais, p. 135.

${ }^{37}$ BARATTA, Alessandro. Criminologia crítica e crítica do direito penal: introdução à sociologia do direito penal. Tradução Juarez Cirino dos Santos. 3. ed. Rio de Janeiro: Revan, 2002, p. 166.
} 
chamados de crimes do colarinho branco -, que permanecem imunes aos processo de criminalização.

À guisa de ilustração do panorama estudado, em uma análise dos dados mais recentes do Departamento Penitenciário Nacional ${ }^{38}$, é possível observar que $55 \%$ da população é formada por jovens entre 18 e 29 anos, 64\% dos presos são negros, $17,75 \%$ concluíram, no máximo, o ensino fundamental e $24 \%$ ainda não concluíram o ensino médio. Não existem dados oficiais com relação à situação econômica da população carcerária, mas sabe-se que não se foge do perfil da estigmatização apresentado.

Sobre os adolescentes em conflito com a lei, em pesquisa realizada pelo Conselho Nacional de Justiça (2012) é possível observar que a maioria é composta por adolescentes de 15 a 17 anos com famílias desestruturadas, defasagem escolar e envolvidos com drogas, sendo que os atos infracionais correspondentes a crimes contra o patrimônio (roubo, furto, entre outros) foram os mais praticados pelos respondentes.

Dentro desse contexto, emerge com nitidez a responsabilidade dos agentes de controle social brasileiro no encarceramento da juventude negra e pobre, reforçando que os contornos históricos e sociológicos da construção da imagem do elemento suspeito são decisivos nas abordagens policiais, o que revela a relação direta com a tendência criminalizadora das minorias estigmatizadas:

Através da análise externa efetuada pela Criminologia Crítica, (onde o sistema penal passa ser objeto de seu estudo) o que se evidenciou foi a seletividade com que é manifesta o poder punitivo do Estado. Este não atua de forma racional, buscando a aplicação igualitária da lei penal ao caso concreto. Ao contrário, seleciona indivíduos de classes baixas da sociedade para serem rotulados como criminosos com o intuito de ocultar a criminalidade daqueles que detêm o poder econômico. ${ }^{39}$

Faz-se mister destacar que todo este processo de seleção não é um fenômeno específico da atividade dos órgãos encarregados do controle institucional da

\footnotetext{
$\overline{38}$ BRASIL. DEPEN - Departamento Penitenciário Nacional do Ministério da Justiça e Segurança Pública. Levantamento nacional de informações penitenciárias. Junho, 2016. Disponível em: http://depen.gov.br/DEPEN/ noticias-1/noticias/infopen-levantamento-nacional-de-informacoes-penitenciarias-016/relatorio_2016_22111. pdf Acesso em: 20 abr. 2018.

39 RODRIGUES, Saulo Tarso. Criminologia: A política criminal alternativa e os princípios de direito penal mínimo de Alessandro Baratta: na busca da (re) legitimação do sistema. São Paulo: Sisan, 2003, p. 123.
} 
criminalidade, mas "uma característica geral dos processos de interação e de comunicação entre os homens", que Sack ${ }^{40}$ define como uma teoria marxista interacionista, em que a divisão dos bens, positivos e negativos, é realizada com base na classe social.

Assim, é possível verificar uma tendência das instâncias formais de controle a selecionar aquele que possui determinado estereótipo, porém, é importante observar que o estigma é construído pela sociedade antes mesmo da atuação estatal. O que se constata, em verdade, é que os próprios pares, sob a influência de fatores históricos, culturais, econômicos e até mesmo midiáticos, acabam por erigir com preconceito a imagem padronizada do criminoso, que inegavelmente coincide com aquela buscada pelos agentes de controle social.

Nota-se, portanto, que se trata de um ciclo vicioso em que a sociedade constrói o padrão a ser perseguido, em seguida o Estado atua sob a influência destes padrões, consequentemente os estigmatizados são selecionados para sofrerem as sanções, corroborando o rótulo fornecido por seus pares, e então continuam a ser taxados com o padrão de criminoso.

Nesse panorama, a desigualdade social, coligada ao sentimento das classes mais baixas de nossa sociedade, no sentido de que a seletividade de nosso sistema penal somente serve para apená-los e aprisioná-los, em oposição à garantia de impunidade às classes mais abastadas, acaba por suscitar a ideia de não ser possível a construção de uma sociedade igualitária em seu aspecto substancial, até porque o Estado, ao ser ineficiente quanto à efetiva redução das desigualdades sociais, adiciona ainda a desigualdade jurídica no tratamento de seus cidadãos. ${ }^{41}$

Segue, no particular, a lição de Becker sobre a injusta seletividade de tratamento pelos aplicadores da lei.

Essas discrepâncias lançam dúvida sobre noções simples relacionadas ao que é certo e o que é errado. Vemos que os próprios atores muitas vezes discordam quanto ao que é desviante, e com frequência duvidam do caráter desviante de um ato. Os tribunais divergem; a polícia tem restrições mesmo quando a lei é clara; aqueles envolvidos na atividade proscrita discordam das definições oficiais. Além disso, constatamos

\footnotetext{
40 SACK, 1971, p. 14 apud BARATTA, Alessandro. Criminologia crítica e crítica do direito penal: introdução à sociologia do direito penal. Tradução Juarez Cirino dos Santos. 3. ed. Rio de Janeiro: Revan, 2002, p. 112.

${ }^{41}$ CONTRUCCI, José Roald. A seletividade do sistema penal no Estado Democrático Brasileiro: uma afronta ao princípio da igualdade. Argumenta Journal Law, Jacarezinho - PR, n. 12, p. 181-208, fev. 2013. Disponível em: http://seer.uenp.edu.br/index.php/argumenta/article/view/166. Acesso em: 20 abr. 2018.
} 
que alguns atos que, por padrões comumente reconhecidos, deveriam claramente ser definidos como desviantes não o são por ninguém. Vemos que impositores da lei e da moralidade muitas vezes contemporizam, permitindo que alguns atos passem despercebidos ou livres de punição porque seria muito difícil averiguá-los; porque possuem recursos limitados e não poderiam perseguir todo o mundo; porque o infrator tem poder suficiente para se proteger contra suas incursões; porque foram pagos para fazer vista grossa ${ }^{42}$.

Em face de tudo quanto foi exposto, verifica-se que os estigmas, preceitos contingentes e volúveis criados com embasamento cultural e histórico negativos, e a credibilidade de que eles têm valor intrínseco do mal, escravizam as pessoas e negam o direito geral, abstrato e democrático, que não conseguiu historicamente desatar-se dos seus valores intrínsecos ${ }^{43}$.

Deveras, é mister concluir que a seletividade do sistema, nada mais é do que consectário lógico desta dependência dos fatores estigmatizantes, tanto da sociedade, quanto dos órgãos de controle, na definição do desvio, bem como na punição de determinados comportamentos em detrimento de outros. Em outras palavras, somente se atingirá o ideal de justiça democrática e igualitária quando ocorrer a libertação das amarras dos preconceitos estereotipados do subjetivo humano, o que permitirá uma aproximação da utópica imparcialidade almejada.

\section{CONSIDERAÇÕES FINAIS}

A atuação do controle social realizado pelo Estado deve ocorrer nas situações em que o conflito se reveste de especial importância, submetendo os infratores às normas de atuação previamente estipuladas de forma a assegurar a objetividade da intervenção, bem como o devido respeito às garantias constitucionalmente previstas, em especial o direito à igualdade de tratamento legal.

Ocorre que, diferentemente do que é esperado e preconizado pelos princípios constitucionais, se observa que a maioria dos sujeitos que respondem a proces-

\footnotetext{
${ }^{42}$ BECKER, Howard Saul. Outsiders: Estudos de sociologia do desvio. Rio de Janeiro: Zahar , 2008. Título original: Outsiders: studies in the sociology of deviance. p. 185.

${ }^{43}$ BACILA, Carlos Roberto. Criminologia e estigmas: um estudo sobre os preconceitos. 4. ed. São Paulo: Atlas, 2015, p. 218.
} 
sos criminais ou cumprem pena possuem um perfil determinado por fatores sociais, sendo em regra pessoas de estratos sociais menos favorecidos, negros e jovens, que traduzem uma clara seletividade do sistema punitivo.

Depreende-se, dessa análise, que as teorias criminológicas apresentadas possuem grande relevância no estudo da estigmatização a partir de perspectivas diferentes. A teoria do Labelling Approach retrata a importância da reação social no processo de estigmatizador do sujeito, atribuindo este fator como causa principal da criminalidade secundária e da reincidência.

A teoria da Inibição Reintegradora, por sua vez, ainda pouco difundida no meio acadêmico, contribui de forma relevante ao reforçar as premissas apresentadas pelo Labelling Approach demonstrando que a rotulação é um fator determinante para a criminalização. A sociedade, ao optar pelo sistema punitivo de cunho repressivo e com finalidade primordialmente retributiva, ao invés de prevenir e reduzir o índice de criminalidade, acaba por provocar um efeito oposto, direcionando o sujeito à adesão de subculturas criminais que impedem a ressocialização e geram reincidência.

Desta feita, tanto a teoria do Etiquetamento, quanto à da Inibição Reintegradora apresentam propostas a fim de minimizar a estigmatização social. A primeira entende que a não intervenção do Estado seria uma opção para amenizar o processo estigmatizador e a consequente criminalidade. Já a segunda preceitua que a intervenção do Estado é necessária, porém, na sequência o sujeito deveria se sujeitar à apreciação do fato pela comunidade, onde passaria por um processo de reintegração por meio da internalização da vergonha gerada pelo crime praticado.

Outrossim, à guisa do conceito de estigma e das teorias apresentadas, verificou-se que há grande influência dos fatores estigmatizantes na seletividade do sistema penal. O estigma acaba funcionando como uma metarregra utilizada tanto para a interpretação do direito, quanto para sua aplicação no caso concreto. Sendo assim, fatores culturais, históricos e econômicos que desfavorecem certos nichos da sociedade são decisivos para a seleção do sistema punitivo.

Deve-se pontuar, por necessário, que a estigmatização não soluciona a problemática da etiologia criminal trazendo uma fórmula lógica sobre os elementos que influenciam a prática do desvio primário, mas, conforme demonstrado, possui forte influência na escolha daqueles sobre os quais a lei recai com mais frequência e intensidade, bem como prejudica a reabilitação destes em face do efeito crimina- 
lizador secundário.

Conclui-se, por fim, que não seria justo responsabilizar somente a seletividade do Estado, como titular do direito penal subjetivo, pelo cenário atual da população carcerária brasileira. É inegável a influência de diversos fatores sociais na formação dos estigmas e desigualdades, previamente construídos e historicamente utilizados. Porém, ainda assim, não é possível eximi-lo da culpa, pois a adoção de ações sociais afirmativas, bem como a garantia do devido processo legal e da defesa eficiente para as classes mais vulneráveis certamente auxiliariam na mitigação das injustiças. Por outro lado, a aplicação efetiva das normas àqueles que estão em situação privilegiada, seja de poder ou econômica, é imperiosa para reduzir a seletividade patente do sistema.

\section{REFERÊNCIAS}

ANDRADE, Vera Regina Pereira de Andrade. A ilusão da segurança jurídica: do controle da violência à violência do controle penal. Porto Alegre: Livraria do Advogado, 1997.

BACILA, Carlos Roberto. Criminologia e estigmas: um estudo sobre os preconceitos. 4. ed. São Paulo: Atlas, 2015.

BARATTA, Alessandro. Criminologia crítica e crítica do direito penal: introdução à sociologia do direito penal. Tradução Juarez Cirino dos Santos. 3. ed. Rio de Janeiro: Revan, 2002.

BECKER, Howard Saul. Outsiders: Estudos de sociologia do desvio. Rio de Janeiro: Zahar, 2008. Título original: Outsiders: studies in the sociology of deviance.

BENEDETTI, Juliana Cardoso. A justiça restaurativa de john braithwaite: Vergonha reintegrativa e regulação responsiva. Revista Direito GV, São Paulo, v. 1, n. 2, p. 209-216, jun. 2005. Disponível em: http://bibliotecadigital.fgv.br/ojs/index.php/revdireitogv/article/view/35237/34037. Acesso em: 16 abr. 2018.

BRAITHWAITE, John. Crime, Shame, and Reintegration. New York: Cambridge University, 1999.

BRASIL. DEPEN - Departamento Penitenciário Nacional do Ministério da Justiça e Segurança Pública. Levantamento nacional de informações penitenciárias. Junho, 2016. Disponível em: http://depen.gov.br/DEPEN/noticias-1/noticias/infopen- 
-levantamento-nacional-de-informacoes-penitenciarias-016/relatorio_2016_22111. pdf Acesso em: 20 abr. 2018.

CONTRUCCI, José Roald. A seletividade do sistema penal no Estado Democrático Brasileiro: uma afronta ao princípio da igualdade. Argumenta Journal Law, Jacarezinho, PR, n. 12, p. 181-208, fev. 2013. Disponível em: http://seer.uenp.edu.br/ index.php/argumenta/article/view/166. Acesso em: 20 abr. 2018.

CNJ - Conselho Nacional de Justiça. Panorama Nacional: A execução de medidas socioeducativas de internação. Programa Justiça ao Jovem. 2012. Disponível em: http://www.cnj.jus.br/images/programas/justiça-ao-jovem/panorama_nacional_justiça_ao_jovem.pdf. Acesso em: 20 abr. 2018.

GOFFMAN, Erving. Estigma: Notas Sobre a Manipulação da Identidade Deteriorada. Rio de Janeiro: LTC, 1988.

LEMERT, Edwin M. Human deviance, social problems, and social control. Londres: Prentice-Hall International, 1967.

MOLINA, Antonio García-Pablos de. O que é criminologia? São Paulo: Revista dos Tribunais, 2013.

RODRIGUES, Saulo Tarso. Criminologia: A política criminal alternativa e os princípios de direito penal mínimo de Alessandro Baratta: na busca da (re) legitimação do sistema. São Paulo: Sisan, 2003.

SANTOS, Juarez Cirino dos. A criminologia radical. 3. ed. Curitiba: ICPC; Lumen Juris, 2008.

SHECAIRA, Sérgio Salomão. Criminologia. 5. ed. rev. São Paulo: Revista dos Tribunais, 2013.

ZAFFARONI, Eugenio Raúl. Em busca das penas perdidas. 5. ed. Rio de Janeiro: Revan, 2001.

ZEHR, Howard. Changing Lenses: A New Focus for Crime and Justice (Trocando as Lentes: um novo foco sobre Crime e a Justiça). Scottsdale, PA: Herald Press. 